\title{
Analysis and forecasts of investment scale and structure in upstream sector for oil companies based on system dynamics
}

\author{
Zhang Baosheng* and Wang Qing \\ School of Business, China University of Petroleum, Beijing 102249, China \\ (C) China University of Petroleum (Beijing) and Springer-Verlag Berlin Heidelberg 2011
}

\begin{abstract}
Oil and gas exploration and production is the most important and key segment in the whole business chain of the petroleum industry. Therefore, oil companies always put much emphasis on making scientific and reasonable decisions about investment scale and structure in the upstream sector, so that they can minimise business risks and obtain high returns. According to the system dynamics theories and methods and based on the actual results from an oil company's practice in China, a system dynamics model is built in this paper for analyzing and forecasting the upstream investment scale and structure for an oil company. This model was used to analyze the investment effect of a large oil company in China, and the results showed that the total upstream investment scale will decline slowly in a short period and the investment proportion of different parts should be adjusted if some influencing factors are taken into account. This application practice was compared with the actual data and indicated that the system dynamics (SD) model presented in this paper is a useful tool for analyzing and forecasting of upstream investment scale and structure of oil companies in their investment decisions.
\end{abstract}

Key words: Oil companies, upstream investment, scale and structure, analysis and forecast, system dynamics

\section{Introduction}

Because of past high oil prices, all the oil companies concentrate their investment on the upstream business and increase the investment strength in oil and gas exploration and development. So, the oil companies pay much attention to the analysis and forecast of upstream investment in terms of scale and structure and then they can take corresponding measures to adjust it according to the changing situations. Many methods are available as analyzing and forecasting methods, such as time series analysis, regression analysis and econometric methods. The System Dynamics (SD) method is often selected for complicated systems, because this method is specially designed for simulating and studying complex systems with multivariable, nonlinear and dynamic characteristics.

The SD method has been used in many cases for analyzing sustainable energy development in China (He et al, 2001; Zhang et al, 2006; Wu et al, 1998; Li et al, 2006; Song et al, 2004; Liu et al, 2004). The SD model was used in agricultural area to study the possible effects of methane utilization in rural areas (Tu and Jia, 2004). In the petroleum and petrochemical industry, the SD method was used for

*Corresponding author. email: bshshysh@cup.edu.cn

Received May 12, 2010 studying the capacity of the sustainable development of the energy industry (Wang et al, 2006; Li and Zhao, 2003; Tan et al, 2009), and for analyzing oil exploration and production and the effects of different government policies (Wang et al, 2001; Zhang et al, 2002; Chen et al, 2002). Some others (Yu et al, 2006; Yuan and Zhang, 2008; Wang et al, 2009; Li et al, 2009) have also undertaken related research work in the applications of system dynamics.

Based on the results from a consulting project in cooperation with a large oil company in China, this paper presents a simulation model, which is built by the SD method, for forecasting and analyzing the investment structure and scale in the upstream sector. After being examined, the model was used in simulating and analyzing the investment scale and structure in the upstream sector for the large oil company, and some suggestions were made on the basis of the simulation calculations.

\section{Analysis of the oil company's upstream investment and building of the system dynamics model}

\subsection{Analysis of oil company's upstream investment and causality of the system dynamics}

The upstream investment of an oil company is focused mainly on exploration and development of oil and gas. So, 
in this paper, the upstream investment system is divided into exploration and development subsystems. There are, of course, some other investments in upstream business, but we did not take them into account in our study. Based on the SD principles (Wang, 1994), we made a further study of the interrelationship among various factors and feedback mechanism in the subsystems. Fig. 1 shows the brief causality among the factors in the exploration investment subsystem.

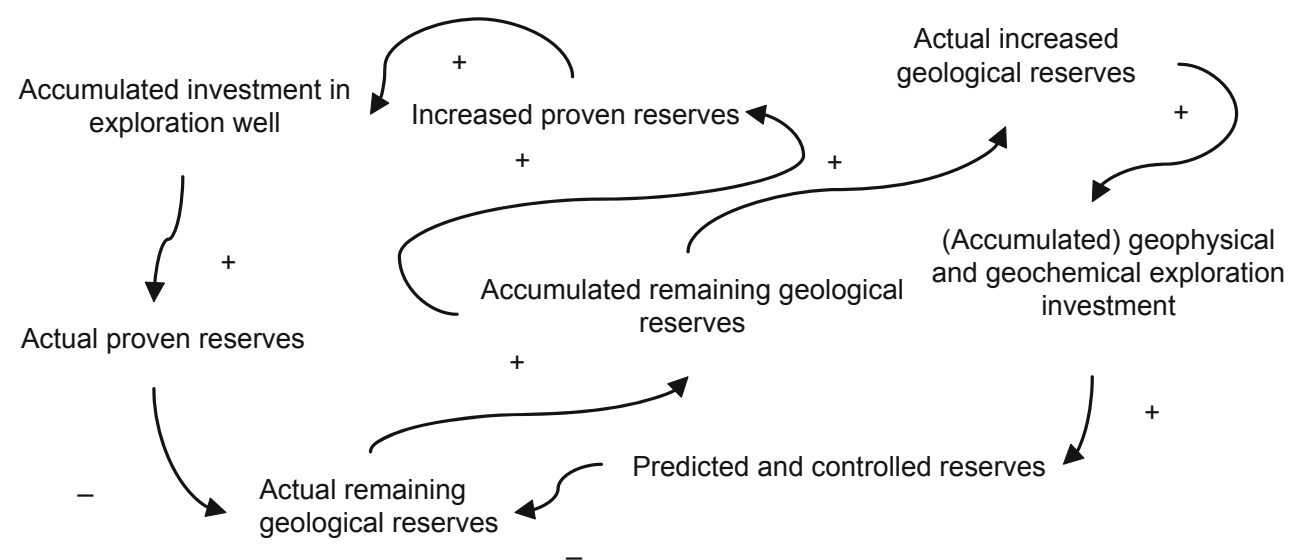

Fig. 1 Diagram of the causalities among the factors in the exploration subsystem

There are two feedback loops in Fig. 1, one is the causality feedback loop of geophysical and geochemical exploration investment, and the other is that of exploration well investment.

The first causality feedback loop shows that the company can add predicted reserves and controlled reserves by increasing investment in geophysical and geochemical exploration by the means of technical innovation and introducing new equipment. The remaining geological reserves will decrease over time, and then the accumulated remaining geological reserves will decline. With the decrease of the remaining geological reserves, the newly increased geological reserves will decrease. Thus, the company will reduce investment in geophysical and geochemical exploration, and increase investment in exploration wells in order to add the reserves further.

From the second causality feedback loop, it can be seen that the company may put more investment in exploration (including drilling more exploration wells) for the purpose of increasing proved reserves. With increasing proved reserves, the remaining geological reserves will decrease and then the accumulated remaining geological reserves will decrease. Owing to decreasing reserves and increasing difficulty in operation, the newly increased proved reserves will decrease. In the period of oil field development, the oil company will reduce the scale of investment in exploration wells and put more investment in development wells to obtain high and stable production.

\subsection{The SD flow graphs}

Based on the relationship between the factors, two SD flow graphs were made to reflect the upstream investment scale and structure in detail (see Fig. 2 and Fig. 3). The whole model starts from the expected oil and gas yield which is taken as an input variable. The intermediate output variables include the expected remaining recoverable reserves, planned newly increased recoverable reserve, expected remaining geological reserves, planned newly additional geological reserves, the actual newly additional geological reserves, and expected remaining proved reserves. The final output variables of the model are the total cost, total profit, the annual total investment in upstream business, the annual direct investment in oil and gas exploration, the annual direct investment in oil and gas development, the annual investment in development wells, the annual investment in exploration wells, the annual investment in geophysical and geochemical exploration.

\subsection{Declaration of variables and analysis of their relationships}

\subsubsection{Variable declaration}

The yield, production capacity and reserves of oil and gas shown in Fig. 2 and Fig. 3 all refer to the total amount. Some other variables are explained as follows:

1) Expected oil and gas yield

The expected oil and gas yield is the predicted oil and gas yield by some geologists, reservoir engineers and related technologists according to the actual oil field conditions.

2) Expected production capacity $\left(C_{\mathrm{E}}\right)$

The expected production capacity refers to the needed capacity in accordance with the expected oil and gas yield.

3) Planned increased production capacity

The planned increased production capacity $\left(C I_{\mathrm{P}}\right)$ means the planned new increase of production according to the difference between the actual production capacity at the beginning of the year $\left(C_{0}\right)$ and the decline amount of production of the year $\left(C_{\mathrm{d}}\right) . C I_{\mathrm{P}}$ can be determined as follows:

$$
C I_{\mathrm{p}}=\left\{\begin{array}{cc}
C_{\mathrm{E}}-\left(C_{0}-C_{\mathrm{d}}\right), & \left(C_{0}-C_{\mathrm{d}}<C_{\mathrm{E}}\right) \\
0 & \text { (otherwise) }
\end{array}\right.
$$

4) Planned production capacity at the end of the year The planned production capacity at the end of the year is 


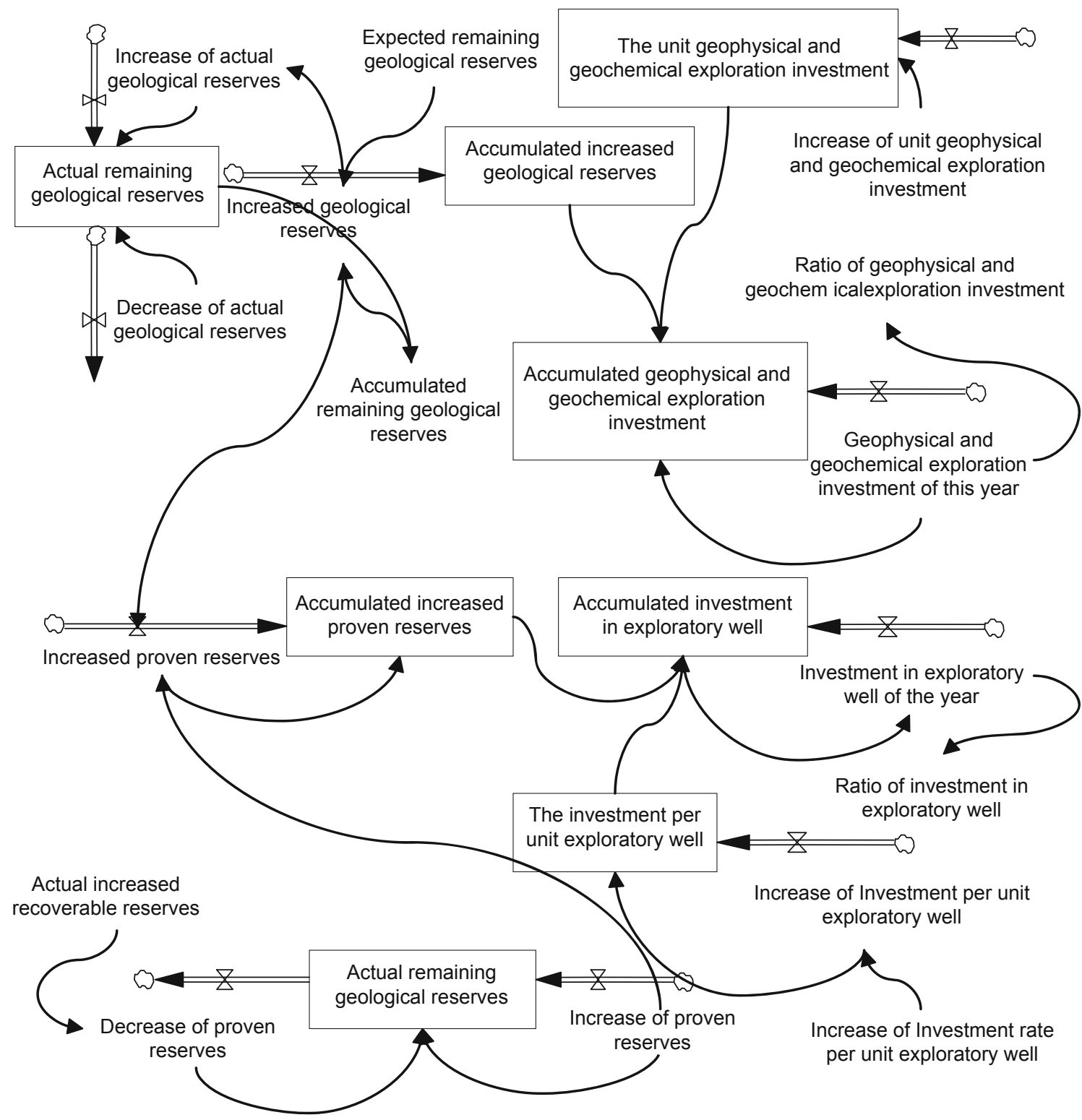

Fig. 2 SD flow graph of oil-gas exploration subsystem

the sum of the actual production capacity at the beginning of the year and the planned increased production capacity.

5) Planned increased recoverable reserve

The planned increased recoverable reserve is the planned increase of recoverable reserve to meet the planned production capacity required at the end of the last year.

\subsubsection{Analysis of variables relationship}

For analysis of the variables relationship, the following principle is used. First, the relationship between variables was determined by the trend analysis method based on the corresponding historical data. Then, appropriate adjustment would be made according to the company's actual situations. As an example, this paper takes the relationship between the increased proven reserve and the annual investment in exploration wells to show the analysis processes (see Fig. 4 and Fig. 5).

Fig. 4 shows the relationship between the increased proven reserve and the annual investment in exploration wells with time. It can be seen that the increased proven reserve had a slow growth in the period from 2002 to 2005 . In the year 2006, a rapid growth occurred. After 2006, it decreased year by year, while the annual investment in exploration wells increased steadily. So it is not a reasonable way to investigate the relationship between annual increased proven reserve and annual investment in exploration wells. Considering the general accumulative effect of investment, in this study, we investigate the relationship between the accumulated increased proven reserve and the accumulated investment in exploration wells (as shown in Fig. 5). Fig. 5 shows that the accumulated increased proven reserve and accumulated investment in exploration is in accordance with each other in growth trend. We can determine the unit investment in exploration wells by calculating the ratio of accumulated investment in exploration wells to accumulated increased proven reserve. In such a way, the abnormal fluctuation of the investment in exploration wells can be avoided. 


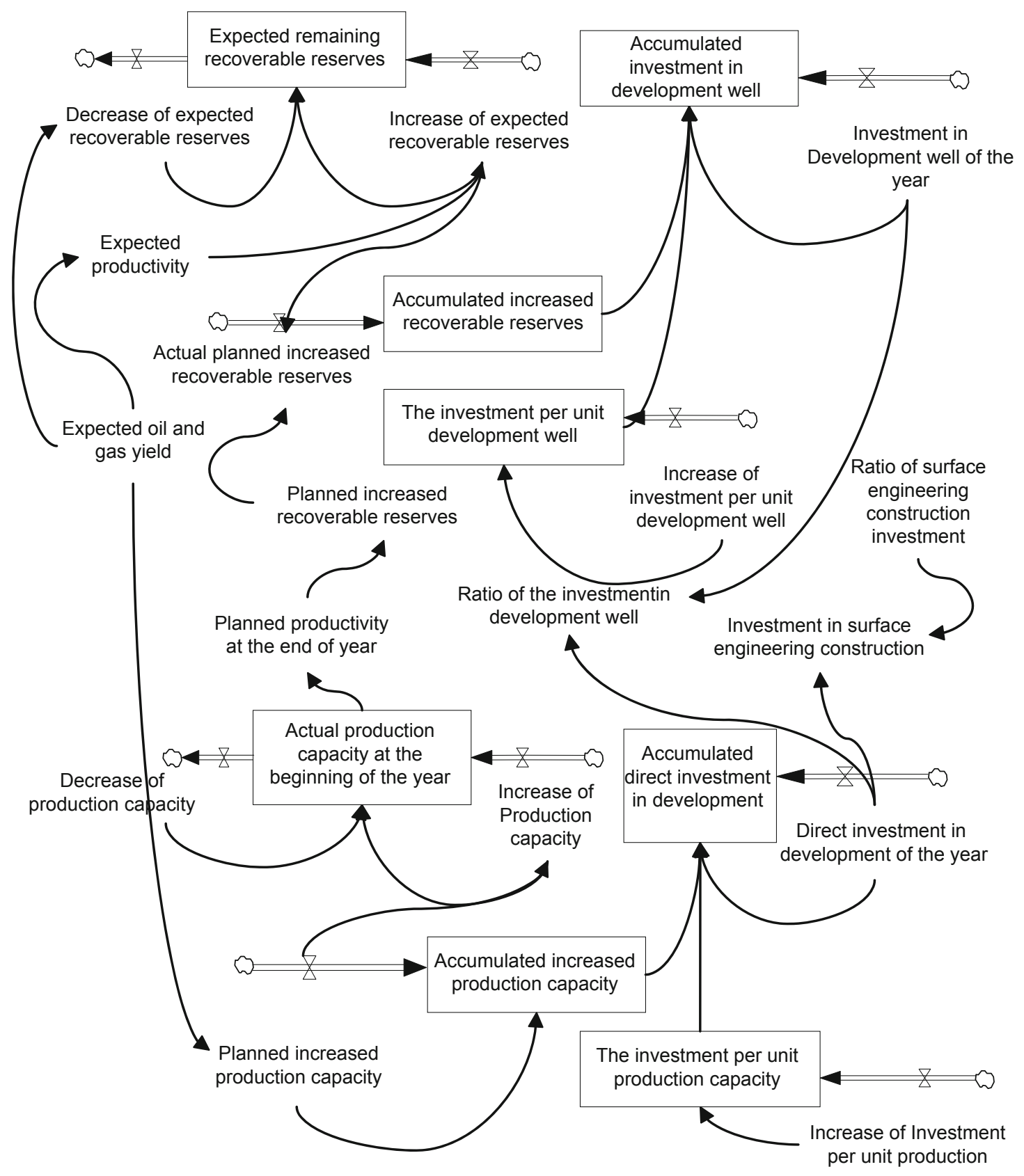

Fig. 3 SD flow graph of oil-gas development subsystem

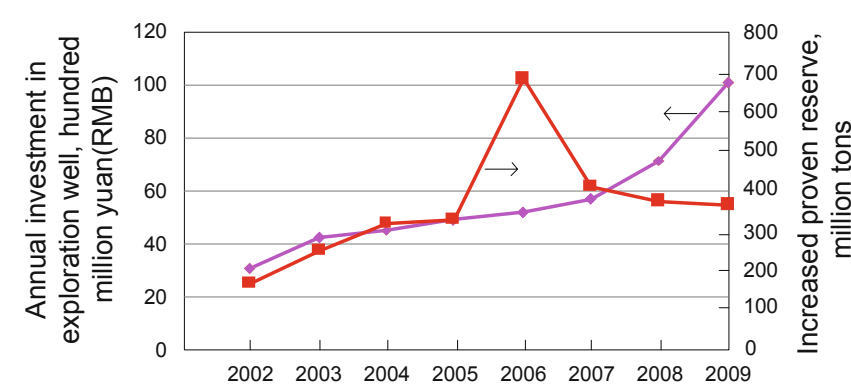

Fig. 4 Relationship between annual increased proven reserve and annual investment in exploration wells

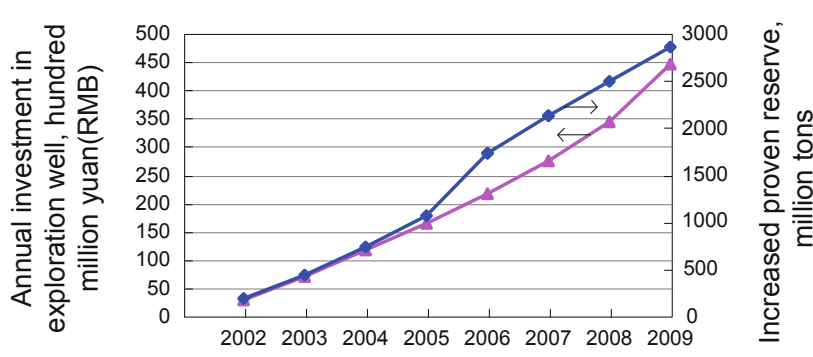

Fig. 5 Relationship between accumulated increased proven reserve and accumulated investment in exploration wells 


\section{Model applications in forecasting and analyzing investment for an oil company}

Based on the SD model described above (see the causalities and flow graphs in Figs. 1, 2 and 3) and the analysis of variables' relationship, a simulation model was built up using the VENSIM software for analysis of upstream investment in oil companies. The simulation model was examined with the related data of 2002 to 2009 from a large oil company in China. The standard deviation between the simulation results and the actual data was smaller than $5 \%$ (Table 1), indicating that the model can be used for analysis of the investment scale and structure for oil companies.

Oil companies often make adjustments in the scale and structure of the upstream investment due to the influence of oil prices, costs and technical progress. This paper takes international oil price, expected oil and gas reserves, exploration and development costs and expected oil and gas yield as the main factors to study their effects on upstream investment. The forecast results of the scales and structures of upstream investment for the large oil company from 2010 to 2012 using the VENSIM SD model are shown in Table 2, Table 3 and Table 4.
Table 1 Comparison of the simulation results with the actual accumulated increased proven reserve

Unit: million tons

\begin{tabular}{c|cccccccc}
\hline Year & 2002 & 2003 & 2004 & 2005 & 2006 & 2007 & 2008 & 2009 \\
Actual data & 195 & 471 & 752 & 1078 & 1749 & 2162 & 2539 & 2907 \\
Simulation results & 192 & 482 & 766 & 1109 & 1672 & 2213 & 2640 & 3015 \\
Relative deviation & $-2.6 \%$ & $2.3 \%$ & $1.9 \%$ & $2.9 \%$ & $-4.9 \%$ & $2.4 \%$ & $4.0 \%$ & $3.7 \%$ \\
\hline
\end{tabular}

Table 2 The forecast results of total upstream investment from 2010 to 2012 Unit: hundred million yuan (RMB)

\begin{tabular}{c|ccc}
\hline Year & 2010 & 2011 & 2012 \\
Baseline scenario & 743.68 & 593.24 & 637.64 \\
Oil price goes up by 10\% & 798.45 & 652.56 & 701.40 \\
Expected oil and gas reverses increase by $10 \%$ & 795.00 & 649.72 & 699.79 \\
Expected oil and gas reverses decrease by $10 \%$ & 704.24 & 550.68 & 591.79 \\
Exploration and development costs increase by 20\% & 772.02 & 630.05 & 683.86 \\
Exploration and development costs decrease by 20\% & 715.70 & 557.30 & 593.02 \\
Expected oil and gas yield increase by 3\% & 758.76 & 608.77 & 654.83 \\
Expected oil and gas yield decrease by 3\% & 712.35 & 559.65 & 621.83 \\
\hline
\end{tabular}

Table 3 The forecast results of exploration and development investment scales from 2010 to 2012

Unit: hundred million yuan (RMB)

\begin{tabular}{|c|c|c|c|c|c|c|}
\hline \multirow{3}{*}{ Scenarios } & \multicolumn{6}{|c|}{ Forecast results } \\
\hline & \multicolumn{3}{|c|}{ Exploration investment } & \multicolumn{3}{|c|}{ Development investment } \\
\hline & 2010 & 2011 & 2012 & 2010 & 2011 & 2012 \\
\hline Baseline scenario & 218.40 & 169.55 & 178.16 & 386.40 & 312.91 & 340.41 \\
\hline Oil price goes up by $10 \%$ & 234.48 & 186.51 & 195.98 & 414.87 & 344.20 & 374.45 \\
\hline Expected oil and gas reserves increase by $10 \%$ & 252.92 & 199.96 & 209.21 & 393.63 & 328.43 & 359.91 \\
\hline Expected oil and gas reserves decrease by $10 \%$ & 186.68 & 142.61 & 150.44 & 386.05 & 305.24 & 330.84 \\
\hline Exploration and development costs increase by $20 \%$ & 230.35 & 183.97 & 196.26 & 397.50 & 328.43 & 359.91 \\
\hline Exploration and development costs decrease by $20 \%$ & 206.55 & 155.58 & 160.88 & 375.50 & 297.65 & 321.40 \\
\hline Expected oil and gas yield increase by $3 \%$ & 221.92 & 173.27 & 181.87 & 395.15 & 321.82 & 350.68 \\
\hline Expected oil and gas yield decrease by $3 \%$ & 219.77 & 166.45 & 174.92 & 359.56 & 288.70 & 330.79 \\
\hline
\end{tabular}

Table 4 The forecast results of exploration and development investment structure

\begin{tabular}{|c|c|c|c|c|c|c|}
\hline \multirow[b]{2}{*}{ Scenarios } & \multicolumn{2}{|c|}{2010} & \multicolumn{2}{|c|}{2011} & \multicolumn{2}{|c|}{2012} \\
\hline & $\begin{array}{l}\text { Exploration } \\
\text { investment }\end{array}$ & $\begin{array}{c}\text { Development } \\
\text { investment }\end{array}$ & $\begin{array}{l}\text { Exploration } \\
\text { investment }\end{array}$ & $\begin{array}{c}\text { Development } \\
\text { investment }\end{array}$ & $\begin{array}{l}\text { Exploration } \\
\text { investment }\end{array}$ & $\begin{array}{r}\text { Development } \\
\text { investment }\end{array}$ \\
\hline Baseline scenario & $29.37 \%$ & $51.96 \%$ & $28.58 \%$ & $52.75 \%$ & $27.94 \%$ & $53.39 \%$ \\
\hline Oil price goes up by $10 \%$ & $29.25 \%$ & $51.34 \%$ & $28.45 \%$ & $52.12 \%$ & $27.37 \%$ & $53.21 \%$ \\
\hline Expected oil and gas reserves increase by $10 \%$ & $31.81 \%$ & $49.51 \%$ & $30.78 \%$ & $50.55 \%$ & $29.90 \%$ & $51.43 \%$ \\
\hline Expected oil and gas reserves decrease by $10 \%$ & $26.51 \%$ & $54.82 \%$ & $25.90 \%$ & $55.43 \%$ & $25.42 \%$ & $55.91 \%$ \\
\hline Exploration and development costs increase by $20 \%$ & $29.84 \%$ & $51.49 \%$ & $29.20 \%$ & $52.13 \%$ & $28.70 \%$ & $52.63 \%$ \\
\hline Exploration and development costs decrease by $20 \%$ & $28.86 \%$ & $52.47 \%$ & $27.92 \%$ & $53.41 \%$ & $27.13 \%$ & $54.20 \%$ \\
\hline Expected oil and gas yield increase by $3 \%$ & $29.25 \%$ & $52.08 \%$ & $28.46 \%$ & $52.86 \%$ & $27.77 \%$ & $53.55 \%$ \\
\hline Expected oil and gas yield decrease by $3 \%$ & $30.85 \%$ & $50.48 \%$ & $29.74 \%$ & $51.59 \%$ & $28.13 \%$ & $53.20 \%$ \\
\hline
\end{tabular}


The model simulation and calculation results indicate that the total upstream investment in 2010 will be 74.369 billion with a structure of $29.37 \%$ in exploration investment and $51.96 \%$ in development investment under the baseline scenario (without regarding to the influence of the related factors). The total upstream investment scales in 2011 and in 2012 will decrease compared with that in 2010, with a downward trend in ratio of the exploration investment and a upward trend in ratio of development investment. Considering the influence of some factors, the oil companies should make some adjustments in investment scale and structure.

\section{(1) Effect of rising international oil price}

The results shown in Table 1 and Table 3 indicate that the upstream investment scale increases with an increase of international oil price, while the ratios of exploration investment and development investment are almost unchanged. When the oil price increases by $10 \%$, the upstream investment scale in 2010 will be $7.4 \%$ higher than that under the baseline scenario, and the scale of exploration investment and that of development investment will both be $7.3 \%$ higher than that under the baseline scenario, while the upstream investment scale in 2011 and 2012 will be $10 \%$ higher than that under the baseline scenario.

(2) Effect from the changes in expected oil and gas reserves

Taking the upstream investment in 2010 for example, the results shown in Table 1 and Table 3 demonstrate that when the expected oil and gas reserve goes up by $10 \%$, the upstream investment scale will be $6.90 \%$ higher than that under the baseline scenario. The exploration investment scale will be $15.80 \%$ higher than that under the baseline scenario, with the ratio of which up $2.44 \%$ over the situation at baseline scenario. Development investment scale will be $1.87 \%$ higher than that under the baseline scenario, and the ratio of which will be up $2.45 \%$ over the situation at baseline scenario.

When the expected oil and gas reserve decreases by $10 \%$, the upstream investment scale will be $5.30 \%$ lower than that under the baseline scenario. The exploration investment scale will be $14.5 \%$ lower than that under the baseline scenario, with the ratio of which declines by $2.86 \%$ compared to the basis situation at baseline scenario. The development investment scale will keep broadly in step with that under the baseline scenario, while the ratio of development investment will increase slightly.

\section{(3) Effect from the changes in exploration and development costs}

Taking the upstream investment in 2010 as an example, this paper analyzes the effect from the changes in exploration and development costs on upstream investment. When the exploration and development costs increase by $20 \%$, the upstream investment scale will be $3.80 \%$ higher than that under the baseline scenario. The exploration investment scale will be $5.45 \%$ and the development investment scale will be $2.87 \%$ higher than that under the baseline scenario, while the proportions of the two parts will be nearly unchanged. When the exploration and development costs decrease by $20 \%$, the upstream investment scale will be $3.70 \%$ lower than that under the baseline scenario. The exploration investment scale will be $5.43 \%$ lower than that under the baseline scenario and the development investment scale will be $2.82 \%$ lower than that under the baseline scenario.

(4) Effect from the changes in expected oil and gas yield

Taking the upstream investment in 2010 for example, the results show that when the expected oil and gas yield rises by $3 \%$, the upstream investment scale will be $2.03 \%$ higher than that under the baseline scenario. The development investment scale will be $2.26 \%$ higher than that under the baseline scenario, and the development investment increases in nearly the same growth ratio as the expected oil and gas yield. When the expected oil and gas yield decreases by $3 \%$, the upstream investment scale will be $4.21 \%$ lower than that under the baseline scenario. The development investment scale will be $6.95 \%$ lower than that under the baseline scenario, while the exploration investment is affected weakly.

From the results, we can see that the most important influence on exploration and development investment may come from the international oil price and expected oil and gas reserves. The expected oil and gas yield is the second influencing factor, and the influence from the exploration and development costs is very weak. When the international oil price increases by $10 \%$, the scale of exploration and development investment will rise by around $7 \%$. If a $10 \%$ change occurs in the expected oil and gas reserves, the variation in exploration and development investment scale will reach roughly $14 \%$. When the expected oil and gas yield varies at a rate of $3 \%$, the change in development investment will be great.

\section{Conclusions}

On the basis of analyzing the characters of upstream investment by oil companies, this paper builds a simulation model by means of SD principles and methods and under help of the software VENSIM. With help of the model described in the paper, the scales and structures of the investment in the upstream sector of a large petroleum company in China were analyzed and forecast. The results indicate that the upstream investment of the oil company is significantly effected by international oil price, expected oil and gas reserves and expected oil and gas yield. The oil company should take some active and reasonable measures to cope with the influences of various factors and make some adjustments on the scale and structure of investment. Under situation of oil price rising and more expected oil and gas reserves being found, the oil company can speed up upstream business, when it has enough technical support capability. All these simulation results and suggestions were discussed with the leaders and experts from the oil company and were given high appraisals. This research shows that the presented SD model is a useful tool in analyzing and forecasting of the scale and structure of upstream investment, with the help of which oil companies can improve the rationality of their investment decisions.

\section{References}

Chen X D, Yu B, Chan G Q, et al. Research on investment size of onshore oilfield development. Operation Research and Management Science. 2002. (02): 122-126 (in Chinese) 
He Y S, Zhang W F and Li G J. The establishment of SD pattern for environmental economy system. Journal of Jiangsu University of Science and Technology. 2001. (04): 63-66 (in Chinese)

Li L Q, Qin G Y and Tian J F. Dynamic model of sustainable development of coal industry based on system dynamics. Journal of Xi'an University of Science and Technology. 2006. (02): 151-153 (in Chinese)

Li M Y, Li K and Yu P L. The study on the forecast capability of system dynamics model of Hubbert curve: Based on the data of American oil production. Systems Engineering. 2009. (02): 102-108 (in Chinese)

Li S and Zhao Y C. System dynamic simulation model for the petrochemical industry's sustainable development. Journal of Jilin University (Engineering and Technology Edition). 2003. (01): 102106 (in Chinese)

Liu Y and Wang Y Q. Research into the sustainable development SD model for oil industry. Journal of Harbin University of Science and Technology. 2004. (06): 79-82 (in Chinese)

Song S T, Wei Y M and Fan Y. Study of system dynamics approach for sustainable development in China: A review China population. Resources and Environment. 2004. (02): $43-49$ (in Chinese)

Tan W F, Xiao R B and Gong X G. A simulation approach to production capacity of oil refining enterprises based on system dynamics. System Simulation Technology. 2009. (02): 85-91 (in Chinese)

Tu G P and Jia R A. Study of feedback structure on the system of agricultural science-technology area with biogas engineering as link. China Biogas. 2004. (01): 25-27 (in Chinese)

Wang G J, Yang J J and Li Q F. System dynamic model for sustainable development of regional economy and its application. Reformation \& Strategy. 2009. (01): 128-132 (in Chinese)

Wang Q F. System Dynamics. Beijing: Tsinghua University Press. 1994. 1-10 (in Chinese)

Wang Y Q, Hu Y Q and Zhao D W. Analysis of sustainable development of oil and gas industry based on system dynamics. Industrial Technology \& Economy. 2006. (08): 66-69 (in Chinese)

Wang Z K, Zhang Z X and Ke Y H. Construction and application of system dynamics model for petroleum exploration and exploitation. Journal of the University of Petroleum, China (Edition of Natural Science). 2001. (02): 125-128 (in Chinese)

Wu Y J, Wang Y, Huang Z Z, et al. A system dynamics simulation model for the sustainable development of China-Energy sector. Computer Simulation. 1998. (01): 11-13 (in Chinese)

Yu J, Zhang Z X and Wu W. Construction of the system dynamics model for oil's exploration and exploitation and policy decision on it. Journal of Wuhan University of Technology (Information \& Management Engineering). 2006. (05): 150-153 (in Chinese)

Yuan L and Zhang B S. Correlation of oilfield service companies' R\&D investment on the basis of competitive speculation. Petroleum Science. 2008. 5(02): 189-194

Zhang B S, Li J and Sun W M. A dynamic model for energy structure analysis. Petroleum Science. 2006. 3(04): 15-20

Zhang Z X, Wang Z K, Hou F H, et al. Construction and application of the sustainable development SD model for the oil's exploration and exploitation. Industrial Engineering Journal. 2002. (2): 1-6

(Edited by Zhu Xiuqin) 